\title{
FAKTOR-FAKTOR YANG MEMPENGARUHI KESEDIAAN BERBELANJA SECARA ONLINE PADA GURU SEKOLAH DASAR (SD) KABUPATEN BANTUL
}

\author{
Bambang Nur Cahyaningrum ${ }^{1}$, Ariyani Wahyu Wijayanti² \\ ${ }^{1}$ Universitas Veteran Bangun Nusantara Sukoharjo \\ bambangnurcahyaningrum@gmail.com \\ ${ }^{2}$ Universitas Veteran Bangun Nusantara Sukoharjo \\ Ariyani.fe.univet@gmail.com
}

\begin{abstract}
The Internet is an electronic means, which can be used for various activities, such as: communication, research, or other business transactions. Internet technology connects thousands of individual computer networks and organizations, worldwide. There are at least six reasons why internet technology is so popular. The six reasons are: the internet has wide connectivity and range, can reduce communication costs, lower transaction costs, can reduce agency costs, interactive, flexible, easy, and have the ability to distribute knowledge more quickly. Online shopping is more interesting with the ever-expanding Internet deployment, at this time. The study looked at whether: risk factors, benefit perceptions, perceptions of ease of use, and reputation perceptions affect consumer confidence in online shopping, as well as to know whether trust affects the willingness to shop online. Population and sample research, is elementary school teacher (SD) in Bantul regency. Data analysis in this research is done by SEM (Structural Equation Model). Respondents were 150 respondents. Perceptions of social trust, perception of benefits, perceptions of ease of use have a positive effect on trust. Risk perception has a negative relationship to trust. Perception of reputation has no positive effect on trust. Trust positively affects the willingness to buy online.
\end{abstract}

Keywords : Online Shopping, Perception, Willingness To Shop.

(C) 2017 JBTI. All rights reserved

Article history : received 13 Sep 2016; revised 13 Nov 2016; accepted 10 Jan 2017

\section{PENDAHULUAN}

Internet merupakan sarana elektronik yang dapat dipergunakan untuk berbagai aktivitas seperti komunikasi, riset, maupun transaksi bisnis lainnya. Teknologi internet menghubungkan ribuan jaringan komputer individual dan organisasi di seluruh dunia. Setidaknya ada enam alasan mengapa teknologi internet begitu popular. Keenam alasan tersebut adalah: internet memiliki konektivitas dan jangkauan yang luas, dapat mengurangi biaya komunikasi, biaya transaksi yang lebih rendah, dapat mengurangi biaya agency, interaktif, fleksibel, mudah, dan memiliki kemampuan untuk mendistribusikan pengetahuan dengan lebih cepat. (Laudon dan Laudon, 2000).

Belanja online semakin menarik dengan pemasangan internet yang semakin meluas pada saat ini. Internet merupakan sebuah jaringan komputer yang saat ini berkembang pesat dari berbagai macam kepentingan bisnis, pendidikan, hingga ke dalam jaringan pemerintahan yang dapat saling berhubungan satu sama lain, dimana dengan jumlah penggunanya bisa berkembang melebihi dari 200 negara (O’Brien, 2003). 
Penggunaan internet untuk aktivitas transaksi bisnis dikenal dengan istilah Electronic Commerce (e-commerce) (McLeod dan Schell, 2004). Menurut Indrajit (2001), karakteristik $e$ commerce terdiri atas: terjadinya transaksi antara dua belah pihak; adanya pertukaran barang, jasa, atau informasi; dan internet sebagai media utama dalam proses transaksi. Dalam praktiknya, transaksi e-commerce dapat terjadi antara organisasi bisnis dengan sesama organisasi bisnis, dan antara organisasi bisnis dengan konsumen (McLeod dan Schell, 2004).

Kondisi tersebut dapat dijadikan pemicu untuk menumbuhkan e-commerce di Indonesia. Dengan semakin banyaknya pengguna internet, diharapkan dapat mempengaruhi perilaku masyarakat dalam melakukan pembelian barang/jasa, yaitu dari pembelian secara konvensional ke e-commerce. Sebagaimana hasil penelitian Liao dan Cheung (2001), bahwa masyarakat di Singapura semakin banyak mempergunakan internet, maka mereka semakin senang melakukan pembelian melalui $e$-shop (toko maya).

Kepercayaan dan keamanan merupakan permasalahan yang cukup pelik bagi retail $e$ commerce berdasarkan survey yang dilakukan oleh Commerce.Net, mengenai Barries and Inhibitors to e-commerce di tahun 1999. Permasalahan seperti ini secara keseluruhan memiliki keterkaitan bagi pedagang dengan konsumennya yang ingin menjalankan bisnisnya secara online, karena konsumen tidak akan membeli jika mereka tidak percaya dengan transaksi berbasis web.

Penelitian ini mengadopsi dari penelitian yang dilakukan Mardhianestry (2011) yang memilih objek penelitian di daerah Yogyakarta dan Jawa Tengah. Adapun sampel dari penelitiannya adalah individu yang pernah melakukan maupun yang baru berniat melakukan online shopping di daerah Yogyakarta dan Jawa Tengah. Hasil dari penelitian yang dilakukan oleh Mardhianestry (2011) menunjukkan bahwa: kepercayaan sosial berpengaruh positif terhadap kepercayaan orang untuk mengakses online shopping; resiko tidak mempengaruhi kepercayaan konsumen dalam menggunakan system online shopping; manfaat yang didapat tidak akan mempengaruhi kepercayaan masyarakat terhadap online shopping; persepsi kemudahan penggunaan berpengaruh positif terhadap persepsi manfaat; persepsi kemudahan tidak terbukti berpengaruh positif terhadap kepercayaan; persepsi reputasi tidak terbukti berpengaruh positif terhadap kepercayaan; kepercayaan berpengaruh positif terhadap sikap; kepercayaan tidak terbukti berpengaruh positif terhadap kesediaan membeli; sikap positif terhadap online shopping akan memungkinkan konsumen melakukan transaksi online shopping. Perbedaan penelitian ini dengan penelitian yang dilakukan oleh Mardhianestry (2011) adalah penelitian ini menggunakan populasi dan sampel Guru Sekolah Dasar (SD) di Kabupaten Bantul.

Berdasarkan uraian di atas, penulis mengambil judul: "Faktor-faktor yang Mempengaruhi Kesediaan Berbelanja Secara Online pada Guru Sekolah Dasar (SD) Kabupaten Bantul“.

\section{KAJIAN TEORI}

\section{A. Pengaruh kepercayaan sosial terhadap kepecayaan.}

Terdapat 3 bentuk utama dalam kepercayaan sosial, yaitu:

1. Kepercayaan khusus, terkadang disebut 'kental' atau kepercayaan pribadi yang kuat.

2. Face-to-face communities, di mana orang saling mengenal dengan baik dan berinteraksi secara dekat setiap hari, dan

3. Perilaku yang dapat dipercaya, bisa diperkuat dengan ancaman sanksi sosial di dalam kelompok.

Keyakinan instrumental atau perhitungan kepercayaan sosial, atau disebut sebagai kepercayaan tit-for-tat, didasarkan pada perhitungan rasional dan biaya-manfaat kepentingan pribadi (Delhey, Jan and Kenneth Newton. 2005).

Menurut Mutz (2005), kebutuhan untuk kontrak hukum, pengawasan, dan litigasi dalam bisnis, telah diganti dengan kepercayaan yang jauh lebih murah dan lebih efisien, dalam melakukan 
bisnis. Pada saat ini, kepercayaan umum dari orang lain menjadi penting. Jika tingkat kepercayaan pada orang lain tinggi, maka hal tersebut akan menciptakan potensi pasar baru untuk barang dan jasa. Peluang baru untuk pertumbuhan ekonomi, melalui transaksi online.

Menurut Slameto (2010) persepsi adalah proses yang menyangkut masuknya pesan atau informasi ke dalam otak manusia, melalui persepsi manusia terus menerus mengadakan hubungan dengan lingkungannya. Hubungan ini dilakukan lewat inderanya, yaitu: indera penglihatan, pendengar, peraba, perasa, dan pencium. Dalam kamus besar psikologi, persepsi diartikan sebagai suatu proses pengamatan seseorang terhadap lingkungan dengan menggunakan indera-indera yang dimiliki, sehingga ia menjadi sadar akan segala sesuatu yang ada dilingkungannya.

Kepercayaan yang tinggi dari orang lain atau masyarakat yang tinggi terhadap online shopping akan mempengaruhi kepercayaan diri terhadap sistem online shopping.

Berdasarkan uraian di atas, maka dapat dirumuskan hipotesis sebagai berikut:

H1: Persepsi kepercayaan sosial (KS) berpengaruh positif terhadap kepercayaan (PK).

\section{B. Resiko berpengaruh negatif terhadap kepercayaan.}

Menurut A. Abas Salim (2007), Resiko merupakan ketidaktentuan "uncertainty" yang mungkin melahirkan peristiwa kerugian "loss". Nilai ekonomi didefinisikan sebagai pengukuran jumlah maksimum seseorang untuk mau mengorbankan barang dan jasanya demi memperoleh barang dan jasa lainnya (Harahap dan Hartono, 2007). Secara formal, konsep ini disebut kesediaan membayar (willingness to pay) seseorang terhadap barang dan jasa yang dihasilkan. Menurut Dowling dan stealin (2001), resiko akan meningkat, dari sejak masih berupa informasi sampai pada keputusan pembelian produk, sehingga resiko diasosiasikan dengan kepercayaan. Persepsi resiko dari konsumen mempengaruhi besarnya kepercayaan konsumen terhadap online shopping.

Berdasarkan teori dan uraian di atas dapat dirumuskan hipotesis berikut ini.

H2: Persepsi resiko (R) mempunyai hubungan negatif terhadap kepercayaan (PK).

\section{Pengaruh persepsi manfaat terhadap kepercayaan.}

Konsep manfaat yang dirasakan, seperti yang didefinisikan dalam model penerimaan teknologi (TAM) oleh Davis (1989), sama dengan teori alasan tindakan (Ajzen dan Fishbein, 1980) dan teori perilaku terencana (Ajzen, 1991), di mana sikap mengarah pada perilaku menurut Baile (2005) menjadi persepsi manfaat. Pemanfaatan merupakan turunan kata dari kata 'Manfaat', yakni suatu penghadapan yang semata-mata menunjukan kegiatan menerima. Penghadapan tersebut pada umumnya mengarah pada perolehan atau pemakaian yang hal-hal yang berguna baik di pergunakan secara langsung maupun tidak langsung agar dapat bermanfaat.

Studi yang dilakukan Tjahjono dan Palupi (2014) menjelaskan bahwa manfaat berdampak pada keinginan menggunakan teknologi. Definisi lain dari manfaat dikeluarkan oleh Dennis Mc Quail dan Sven Windahl (2007), yakni: "Manfaat merupakan harapan sama artinya dengan explore (penghadapan semata-mata menunjukan suatu kegiatan menerima)". Menurut Gefen (2004), kepercayaan pengguna dapat diprediksi yang berhubungan dengan manfaat yang akan diperoleh.

Keyakinan akan manfaat terhadap suatu sistem sebagai landasan timbulnya kepercayaan terhadap sistem tersebut.

Berdasarkan teori dan uraian di atas dapat dirumuskan hipotesis berikut ini:

H3: Persepsi manfaat (PM) berpengaruh positif terhadap kepercayaan (PK).

\section{Pengaruh persepsi kemudahan penggunaan terhadap persepsi manfaat.}

Model perilaku pembelian online dapat dikembangkan dengan TAM (technology acceptance model). TAM berkaitan dengan variabel eksternal yang mempengaruhi persepsi kemudahan penggunaan dan persepsi manfaat. Menurut Davis dalam Kusumawati (2003), persepsi 
kemudahan adalah derajat kepercayaan seseorang bahwa menggunakan suatu sistem tertentu akan bebas dari usaha. Beberapa penelitian di Indonesia dilakukan Palupi dan Tjahjono (2008) dan Tjahjono dan Wulandari (2008) tentang persepsi kemudahan teknologi berpengaruh positif pada intensi menggunakan teknologi.

Konsumen akan berpikir apabila konsumen menggunakan online shopping dengan mudah, maka konsumen akan merasakan manfaat dari online shopping tersebut. Jika konsumen berpersepsi bahwa menggunakan online shopping itu mudah, maka dipersepsikan bahwa online shopping tersebut memberikan manfaat.

Berdasarkan teori dan uraian di atas, dapat dirumuskan hipotesis berikut ini:

H4: Persepsi kemudahan penggunan (PKP) berpengaruh positif terhadap persepsi manfaat (PM).

\section{E. Pengaruh persepsi kemudahan penggunaan terhadap kepercayaan.}

Menurut Davis dalam Kusumawati (2003), persepsi kemudahan adalah tingkat keyakinan seseorang, yaitu dengan menggunakan sistem tertentu akan bebas dari usaha.

Menurut penelitian Caldwell, Helen M. (2000), faktor-faktor yang mungkin mempengaruhi kepercayaan dari penjual sebelumnya untuk melakukan transaksi, disebut sebagai isyarat. Studi mereka menunjukkan bahwa isyarat-isyarat seperti jaminan produk, keamanan web untuk transaksi, dan proses pemesanan penting untuk memulai hubungan, karena adanya kepercayaan di pemasaran online.

Proses pemesanan tersebut di atas, berkaitan dengan kemudahan penggunaan atau pengoperasian dalam melakukan online shopping. Jika konsumen merasa mudah mengoperasikan online shopping, kemudian akan tumbuh rasa percaya terhadap online shopping tersebut.

Berdasarkan teori dan uraian di atas, maka dapat dibuat hipotesis sebagai berikut:

H5: Persepsi kemudahan penggunaan (PKP) berpengaruh positif terhadap kepercayaan (PK).

\section{F. Pengaruh reputasi terhadap kepercayaan.}

Reputasi didefinisikan seba gai keseluruhan kualitas atau karakter yang dapat dilihat atau dinilai secara umum oleh masyarakat (Malaga, 2001). Penelitian Dharma (2006), mengemukaan bahwa temuan ini menunjukkan tampilan muka situs e-commerce yang dipersepsikan sebagai pihak yang bereputasi baik, akan menimbulkan trust. Kesaksian konsumen tentang pengalaman bertransaksi di toko online, merupakan salah satu hal yang dilakukan situs online shopping, untuk mempersepsikan dirinya memiliki reputasi baik. Online shopping yang mempunyai reputasi yang baik, akan dipercaya oleh masyarakat bahwa online shopping tersebut menyediakan informasi yang benar, menyediakan informasi yang dibutuhkan konsumen, dan melindungi informasi-informasi yang berkaitan dengan konsumen.

Berdasarkan alasan di atas, maka penulis membuat hipotesis sebagai berikut:

H6: Persepsi reputasi (PR) berpengaruh positif terhadap kepercayaan (PK).

\section{G. Pengaruh kepercayaan terhadap kesediaan membeli.}

Teknologi Acceptence Model diperkenalkan pertama kali oleh Fred Davis pada tahun 1986. TAM dikembangkan untuk melihat pengaruh variable perceived ease of use (persepsi kemudahan untuk menggunakan), perceived usefullness (persepsi pada daya guna) terhadap variable behavior intention (niat untuk menggunakan) teknologi informasi. Resiko (risk) transaksi dan kepercayaan (trust) transaksi online shopping merupakan hal sangat dipertimbangkan dalam melakukan transaksi maya (virtual) karena jarak, kemampuan teknologi dalam memfasilitasi transaksi, layanan yang tidak bertatap muka dengan penjual secara langsung, dan banyak hal yang dipertimbangkan pembeli 
dalam transaksi melalui online shopping. Model TAM yang dikembangkan dari teori psikologis, menjelaskan perilaku pengguna computer, yaitu berlandaskan pada kepercayaan (belief), sikap (attitude), intensitas (intention) dan hubungan perilaku pengguna (user behavior relationship). Pada saat konsumen telah mempercayai system online shopping, maka dapat menimbulkan niat untuk melakukan transaksi melalui online shopping. Berdasarkan argumen-argumen di atas, maka penulis membuat hipotesis sebagai berikut:

H7: Persepsi kepercayaan (PK) berpengaruh positif terhadap kesediaan membeli secara online (KM).

\section{H. Model Penelitian.}

Model penelitian yang digunakan, adalah sebagai berikut:

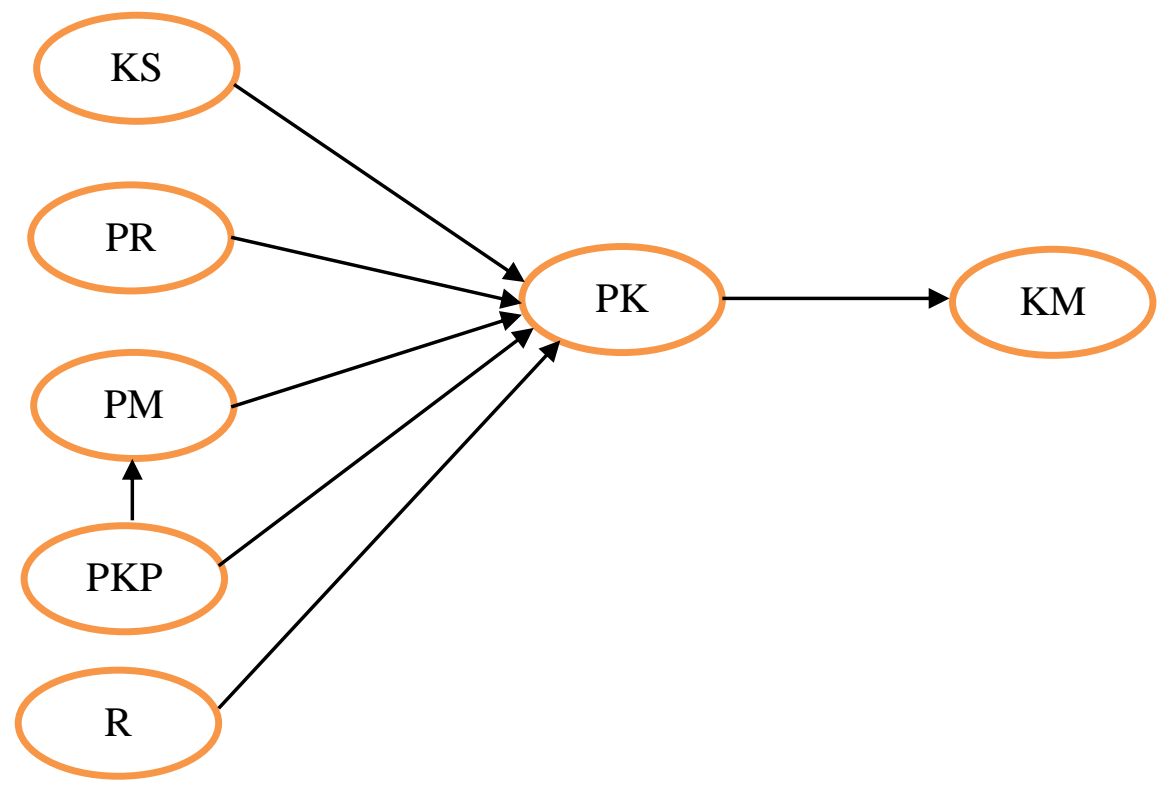

\section{Keterangan:}

$$
\begin{aligned}
& \text { KS }=\text { Kepercayaan Sosial } \\
& \text { PR }=\text { Persepsi Reputasi } \\
& \text { PM }=\text { Persepsi Manfaat } \\
& \text { PKP }=\text { Persepsi Kemudahan Penggunaan } \\
& \text { R } \quad \text { Resiko } \\
& \text { PK = Persepsi Kepercayaan } \\
& \text { KM }=\text { Kesediaan Membeli }
\end{aligned}
$$

Gambar 1 Model Penelitian 


\section{METODE PENELITIAN}

\section{A. Populasi dan Sampel Penelitian}

Populasi yang digunakan dalam penelitian ini, adalah semua guru Sekolah Dasar yang sudah pernah melakukan maupun yang baru berniat, melakukan kegiatan online shopping.

Mengingat adanya keterbatasan dalam melakukan penelitian ini, maka ruang lingkup populasi dipersempit, berdasarkan sampel pada Guru Sekolah Dasar yang pernah melakukan maupun yang berniat melakukan online shopping, di Kabupaten Bantul Yogyakarta.

Teknik penentuan sampel menggunakan teknik accidental sampling. Metode accindental sampling adalah metode pemilihan sampel, dari elemen populasi yang datanya mudah diperoleh peneliti, dengan mendatangi instansi-instansi Sekolah Dasar di Kabupaten Bantul. Metode yang digunakan adalah non-probability sampling yaitu convenience sampling. Convenience sampling adalah pengambilan sampel, yang dilakukan dengan memilih sampel bebas sekehendak penelitinya.

\section{B. Sumber Data dan Teknik Pengambilan Sampel}

Data yang digunakan dalam penelitian adalah data langsung yang diperoleh dari sumber data pertama yang ada di lokasi penelitian atau obyek penelitian. Teknik pengambilan sampel dengan menggunakan teknik aksidental didasarkan pada kemudahan/convenience.

Penentuan ukuran sampel dalam penelitian ini mengacu pada pendapat Roscoe (1975), yang dikutip Uma Sekaran (2006). Roscoe memberikan acuan umum dalam penelitian multivariat (termasuk analisis regresi berganda), ukuran sampel sebaiknya 10 kali lebih besar dari jumlah variabel dalam penelitian. Dalam penelitian ini terdapat 7 variabel, sehingga minimal sampelnya adalah $7 \times 10=70$ sampel. Responden pada penelitian sebanyak 150 orang.

\section{Teknik Pengumpulan Data}

Instrument penelitian menurut Sukmadinata (2010), adalah berupa tes yang bersifat mengukur, karena berisi tentang pertanyaan dan pernyataan yang alternatif jawabannya memiliki standard jawaban tertentu, benar salah maupun skala jawaban. Instrument penelitian berisi jawaban skala, berupa pertanyaan atau pernyataan yang jawabannya berbentuk skala deskriptif ataupun skala garis. Menurut Sugiono (2009), instrument penelitian adalah suatu alat yang digunakan untuk mengukur fenomena alam maupun sosial yang diamati, secara spesifik fenomena ini disebut variabel penelitian.

Pengumpulan data dalam penelitian ini menggunakan metode angket atau kuesioner. Kuesioner atau angket pada penelitian ini menggunakan skala likert yang biasa digunakan untuk mengukur sikap, pendapat, dan ataupun persepsi responden (Tjahjono, 2015). Kuesioner dalam rangka pengumpulan data pada penelitian ini, menggunakan penskoran dengan skala Likert, skala garis dari nilai 1 sampai dengan 6 , untuk jawaban 'sangat tidak setuju' sampai dengan 'sangat setuju'.

Sebelum data yang masuk digunakan, peneliti menyeleksi kuesioner untuk mendapatkan kuesioner yang memenuhi syarat seperti identitas, item pertanyaan, usia, pendidikan, umur, jenis kelamin sudah terisi dengan lengkap.

\section{Variabel Sampel}

Variabel yang akan diteliti dalam penelitian ini, diklasifikasikan sebagai berikut: 
1) Variabel dependen, yaitu kesediaan membeli (willingness to buy) secara online.

2) Variabel independen, terdiri atas: kepercayaan sosial (social trust), persepsi kepercayaan (trust), resiko (risk), persepsi reputasi (reputation), persepsi kemudahan penggunaan dan persepsi manfaat.

\section{E. Teknik Analisis Data}

Teknik analisis pada penelitian ini adalah teknik analisis SEM (Structural Equation Model), dengan menggunakan tools Amos (Wijanto, 2008).

1) Langkah awal, melihat apakah data reliabel dan valid tidak, dengan melakukan uji validitas dan uji reliabilitas.

2) Langkah kedua, melakukan uji kesesuaian dan uji statistik terhadap model penelitian, berdasarkan indeks kesesuaian dan cut-off value.

a. X2-Chi Square Statistic, model dipandang baik atau memuaskan apabila nilai chi square yang dihasilkan rendah. Berdasarkan probabilitas dengan cut-off value sebesar $\mathrm{p}>0,05$.

b. RMSEA (The Root Mean Square Error of Approximation), menunjukkan goodness of fit yang dapat diharapkan, apabila model diestimasi dalam populasi. Nilai RMSEA yang sama atau lebih kecil dari $0,08(\leq 0,08)$, adalah indeks yang menjadi ukuran untuk dapat diterimanya sebuah model, yang menunjukkan sebuah close fit dari model tersebut berdasarkan degrees of freedom.

c. GFI (Goodness of Fit Index), merupakan ukuran non statistical dengan rentang nilai dari 0 (poor fit) sampai dengan 1.0 (perfect fit). Dalam indeks ini nilai yang tinggi merupakan better fit, atau semakin tinggi nilainya semakin baik. GFI $\geq 0.90$ merupakan good fit, sedangkan nilai $0.80 \leq$ GFI $<0.90$ adalah marginal fit .

d. AGFI (Adjusted Goodness of Fit Index), nilainya berkisar antara 0 sampai dengan 1, nilai lebih tinggi adalah lebih baik. AGFI $\geq 0.90$ adalah good fit, sedangkan nilai $0.80 \leq$ AGFI $<0.90$ adalah marginal fit.

e. TLI atau NNFI (Tucker-Lewis Index atau Non-Normed Fit Index). Nilainya antara 0 sampai dengan 1 , dengan nilai yang lebih tinggi lebih baik. TLI $\geq 0.90$ merupakan good fit, sedangkan nilai $0.80 \leq$ TLI $<0.90$ adalah marginal fit.

f. CFI (Comparative Fit Index). Nilainya antara 1 sampai dengan 1, dengan semakin tinggi nilainya adalah semakin baik. CFI $\geq 0.90$ merupakan good fit, sedangkan $0.80 \leq \mathrm{CFI}<$ 0.90 adalah marginal fit.

3) Interpretasi model

Langkah selanjutnya adalah menginterpretasikan model solusi standard, yaitu mengukur besarnya pengaruh atau kontribusi variabel indikator terhadap variabel laten dan mengukur besarnya pengaruh antar variabel laten.

\section{F. Teknik Pengujian Data dan Hipotesis}

Sebelum data diolah dan dianalisis, terlebih dahulu dilakukan pengujian untuk mengetahui kualitas dan keunggulan data respoden dalam menjawab kuesioner, melalui uji validitas (test of validity) dan uji reliabilitas (test of reliability).

1) Uji validitas

Uji validitas adalah suatu ukuran, yang menunjukkan tingkat kesahihan suatu instrument. Menurut Sekaran dan Bougie (2010). Validitas adalah tingkat ketepatan alat ukur penelitian tentang arti atau isi yang sebenarnya diukur. Uji validitas untuk mengukur ketepatan dalam 
penggunaan pernyataan maupun pertanyaan di dalam kuesioner untuk memperoleh data primer. Kuesioner disebut valid apabila pertanyaan-pertanyaan dalam kuesioner mampu mengungkapkan hal-hal yang akan diukur dengan kuesioner tersebut.

Teknik pengukuran validitas pada penelitian ini adalah dengan Confirmatory Factor Analysis (CFA), menggunakan proses Struktural Equation Modelling (SEM). CFA adalah untuk menguji apakah suatu konstruk mempunyai uni-dimensionalitas atau apakah indikator-indikator pertanyaan yang digunakan dapat mengkonfirmasikan sebuah konstruk atau variabel (Ghozali, 2013). Sebagai syarat untuk pengujian CFA, Kaiser-Meyer-Olkin (KMO) and Bartlett's untuk korelasi antar variabel yang diinginkan adalah diatas 0,5 dan tingkat signifikansi penelitian adalah di bawah 0,05 .

Uji validitas yang digunakan pada penelitian ini adalah validitas konstruk. Dalam uji validitas konstruk, menjelaskan validitas sebagai kualitas yang diukur oleh sebuah pengujian, serta menilainya dengan memperlihatkan bahwa konstruk tertentu yang dapat diterangkan bisa menyebabkan baik buruknya penampilan dalam pengujian. Konstruk adalah perangai yang tidak bisa diamati, yang menggambarkan perilaku. Validitas konstruk terdiri: validitas konvergen dan validitas diskriminan. Validitas konvergen terjadi apabila dari hasil yang didapatkan melalui olah data terdapat dua insturmen penelitian atau variabel yang memiliki keterkaitan (Sekaran dan Bougie, 2010). Dalam rangka melihat keterkaitan pada validitas konvergen, menggunakan analisis faktor. Terdapat dua jenis analisis faktor yaitu: EFA (exploratory factor analysis) dan CFA (confirmatory factor analysis). Pada penelitian ini menggunakan CFA dalam rangka menunjukkan keterkaitan antara variabel. Menurut Hair et al. (2010) angka minimal dari factor loading pada CFA adalah 0,5

2) Uji reliabilitas

Uji reliabilitas adalah suatu alat pengukur, yang menunjukkan akurasi, konsistensi dan ketepatan dari pengukuran.

Uji reliabilitas adalah proses yang dilakukan untuk menguji keandalan data (Sekaran dan Bougie 2010). Hal yang dijadikan acuan pada uji reliabilitas ini adalah Cronbach's alpha dari analisis data. Cronbach's alpha merupakan gambaran seberapa besar faktor keterhubungan antara suatu variabel dengan variabel lainnya. Menurut Sekaran dan Bougie (2010), uji reliabilitas merupakan uji untuk mengetahui kebaikan dari suatu alat pengukur, dapat dilihat dari konsistensi dan stabilitas suatu alat ukur. Konsistensi sebuah alat ukur dalam mengukur fenomena yang ada. Reliabilitas mengukur tingkat stabilitas suatu alat ukur untuk mengukur suatu konsep tetap sama, kapan pun dan dimanapun suatu penelitian dilakukan. Penelitian ini pengujian reliabilitasnya menggunakan Cronbach's alpha. Alasannya karena uji Cronbach's alpha merupakan teknik pengujian keandalan kuesioner yang paling sering digunakan (Sekaran dan Bougie, 2010). Nilai Cronbach's alpha yang menjadi acuan adalah di atas 0,70. Nilai tersebut sesuai dengan pernyataan Hair et al. (2007), bahwa batas bawah untuk Cronbach's alpha adalah 0,70 .

Menurut Nunally (dalam Ghozali, 2013), Cronbach's Alpha dikatakan baik apabila dinyatakan lebih dari 0,7. Pengukuran level reliabilitas berdasarkan nilai perhitungan Cronbach, adalah sebagai berikut:

Tabel 1

Level Reliabilitas

\begin{tabular}{|l|l|l|}
\hline \multicolumn{1}{|c|}{ No } & \multicolumn{1}{|c|}{ Nilai Cronbach Alpha } & \multicolumn{1}{c|}{ Level Reliabilitas } \\
\hline 1 & $>0,90$ & Sempurna \\
\hline 2 & Antara $0,70-0,90$ & Tinggi \\
\hline
\end{tabular}




\begin{tabular}{|l|l|l|}
\hline 3 & Antara $0,50-0,70$ & Moderat \\
\hline 4 & $<0,50$ & Rendah \\
\hline
\end{tabular}

3) Uji Hipotesis

Pengujian hipotesis pada penelitian ini menggunakan analisis multivariat Structural Equation Modeling (SEM). SEM merupakan teknik statistik multivariat kombinasi antara analisis faktor dengan analisis regresi, untuk menguji hubungan antar variabel pada sebuah model, baik antar indikator dengan konstruknya maupun hubungan antar konstruk (Santoso, 2014). Alat analisis menggunakan software SPSS versi 17 dan amos versi 22. SPSS sebagai pengolah data utama uji kualitas data dan sebagai data input ke aplikasi amos. Amos untuk uji hipotesis data. Asumsi SEM dalam uji hipotesis pada aplikasi amos, ukuran sampel harus lebih dari 100 (>100) dan normalitas data (data normal). Penelitian ini adalah deskriptif kuantitatif yang bersumber pada opini responden yang bersifat kualitatif, sehingga tidak memerlukan kecermatan tinggi, hanya merupakan penelitian sosial, sehingga nilai alpha ditentukan sebesar $5 \%$ atau 0,05 .

\section{HASIL DAN PEMBAHASAN}

\section{A. Hasil Pengumpulan Data}

Pengumpulan data dalam penelitian ini menggunakan kuesioner. Metode pengumpulan sampel, dilakukan dengan cara aksidental sampling. Responden adalah guru Sekolah Dasar di Kabupaten Bantul, yang pernah melakukan maupun yang baru berniat melakukan kegiatan online shopping. Adapun hasil kuesioner yang berhasil diterima dan dikembalikan kepada peneliti, adalah sebagai berikut:

Tabel 2

Hasil Pengumpulan Data

\begin{tabular}{|l|c|c|}
\hline \multicolumn{1}{|c|}{ Keterangan } & Jumlah & Prosentase \\
\hline Kuesioner yang disebar & 180 & $100 \%$ \\
\hline Kuesioner yang tidak dikembalikan & 9 & $5 \%$ \\
\hline Kuesioner yang kembali & 171 & $\%$ \\
\hline Kuesioner yang memenuhi syarat & 150 & $\%$ \\
\hline Kuesioner yang pengisiannya tidak lengkap & 21 & $\%$ \\
\hline
\end{tabular}

\section{B. Hasil Uji Instrumen Penelitian}

Pengujian validitas dilakukan pada tujuh variabel dalam penelitian ini. Hasil uji validitas menunjukkan bahwa semua item pernyataan memiliki validitas yang baik. Uji reliabilitas yang dilakukan didapatkan hasil yaitu: reliabilitas kepercayaan sosial sebesar 0,751; reliabilitas persepsi reputasi sebesar 0,802 , reliabilitas persepsi manfaat sebesar 0,897 ; reliabilitas persepsi kemudahan penggunaan sebesar 0,822 ; reliabilitas resiko sebesar 0,885 ; reliabilitas persepsi kepercayaan sebesar 0,852; dan reliabilitas kesediaan membeli sebesar 0,848 . 


\section{Full Structural Equation Model Analysis}

Analisis model persamaan struktural secara penuh (full structural equation model analysis) dapat dilihat pada gambar 1 sebagai berikut:

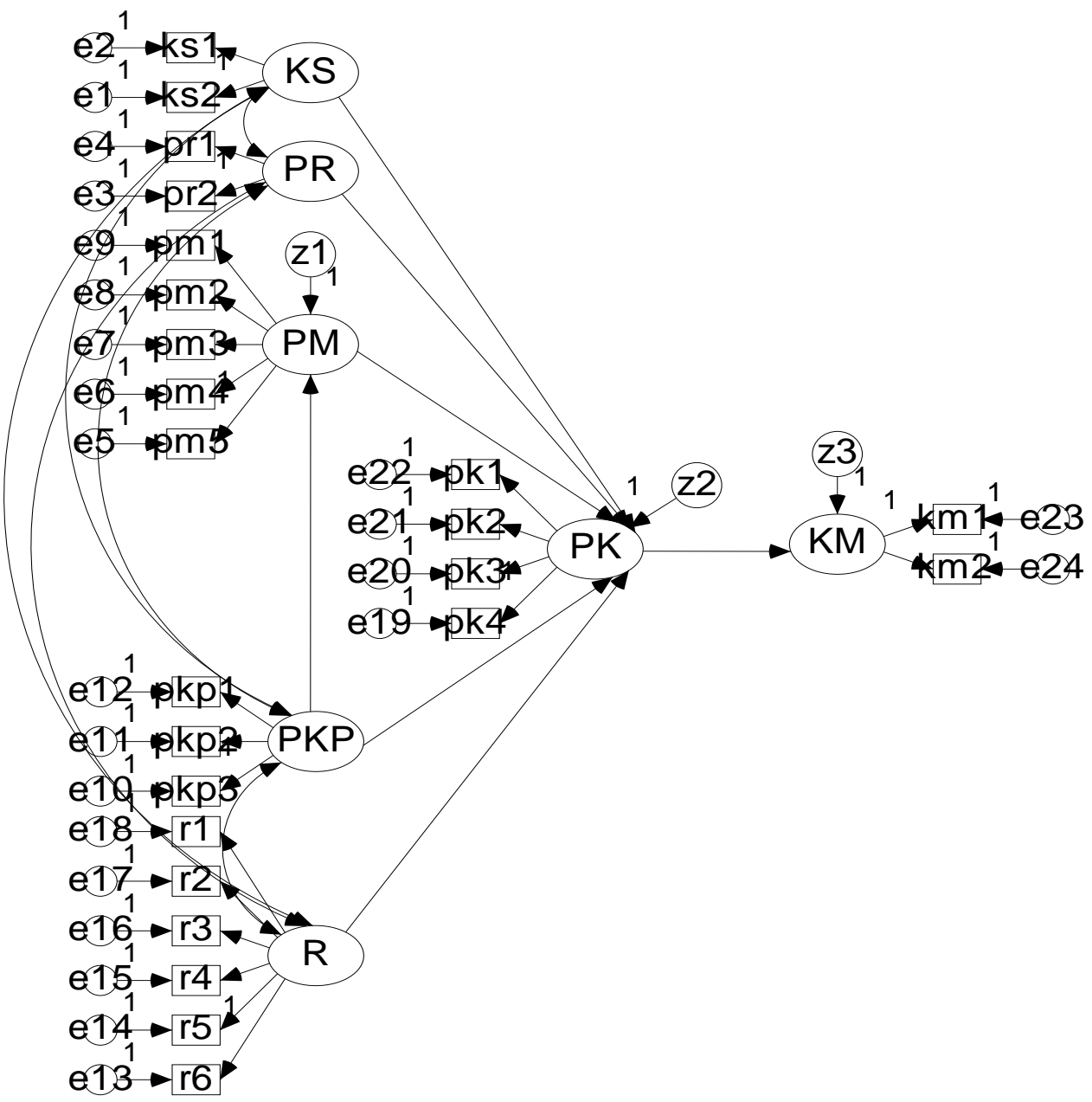

Gambar 1 Full Structural Equation Model

Sumber: data primer diolah 2017 (Output AMOS 22.0)

\section{Penilaian Kriteria Goodness of Fit Index}

Setelah data dinyatakan berdistribusi normal, maka model dapat diuji kesesuaiannya, dengan melihat nilai Goodness of Fit. Kriteria yang menjadi acuannya yaitu: chi square, probabilitas, CMIND/DF, GFI, RMSE, AGFL, TLI dan CFI yang dihasilkan.

Tabel 3

Model Fit Summary

CMIN

\begin{tabular}{|l|rrrrr|}
\hline Model & NPAR & CMIN & DF & P & CMIN/DF \\
\hline Default model & 61 & 261.133 & 239 & .156 & 1.093 \\
Saturated model & 300 & .000 & 0 & & \\
Independence model & 24 & 1989.660 & 276 & .000 & 7.209 \\
\hline
\end{tabular}

Sumber: data primer diolah 2017 (Output AMOS 22.0) 
Tabel 4

Model Fit Summary

RMR, GFI

\begin{tabular}{|l|cccc|}
\hline Model & RMR & GFI & AGFI & PGFI \\
\hline Default model & .082 & .869 & .836 & .692 \\
Saturated model & .000 & 1.000 & & \\
Independence model & .226 & .335 & .277 & .308 \\
\hline
\end{tabular}

Sumber: data primer diolah 2017 (Output AMOS 22.0)

\section{Tabel 5}

Model Fit Summary

Baseline Comparisons

\begin{tabular}{|l|rrrrr|}
\hline Model & $\begin{array}{r}\text { NFI } \\
\text { Delta1 }\end{array}$ & $\begin{array}{r}\text { RFI } \\
\text { rho1 }\end{array}$ & $\begin{array}{r}\text { IFI } \\
\text { Delta2 }\end{array}$ & $\begin{array}{r}\text { TLI } \\
\text { rho2 }\end{array}$ & CFI \\
\hline Default model & .869 & .848 & .987 & .985 & .987 \\
Saturated model & 1.000 & & 1.000 & & 1.000 \\
Independence model & .000 & .000 & .000 & .000 & .000 \\
\hline
\end{tabular}

Sumber: data primer diolah 2017 (Output AMOS 22.0)

Tabel 6

Model Fit Summary

RMSEA

\begin{tabular}{|l|r|r|r|r|}
\hline Model & RMSEA & LO 90 & HI 90 & PCLOSE \\
\hline Default model & .025 & .000 & .043 & .993 \\
\hline Independence model & .204 & .196 & .213 & .000 \\
\hline
\end{tabular}

Sumber: data primer diolah 2017 (Output AMOS 22.0)

Berikut merupakan ringkasan perbandingan model yang dibangun dengan cut-of goodness-of-fit indixs yang ditetapkan: 
Tabel 7

Hasil Uji Goodness of Fit Index

\begin{tabular}{|c|c|c|c|}
\hline Indeks & Cut off Value & Hasil & Evaluasi Model \\
\hline Chi Square & $\begin{array}{c}\text { df }=239 \text { adalah } \\
276,0624 \text { (tabel) }\end{array}$ & 261,133 & Baik \\
\hline Probability & $\geq 0,05$ & 0,156 & Baik \\
\hline CMIN/DF & $\leq 2,00$ & 1.093 & Baik \\
\hline GFI & $\geq 0,90$ & 0,869 & Marginal \\
\hline AGFI & $\geq 0,90$ & 0,836 & Marginal \\
\hline RMSA & $\leq 0,08$ & 0,025 & Baik \\
\hline TLI & $\geq 0,90$ & 0,985 & Baik \\
\hline CFI & $\geq 0,90$ & 0,987 & \\
\hline & & & \\
\hline
\end{tabular}

Sumber: data diolah, 2017

Berdasarkan uji kesesuaian model, model yang dipakai pada penelitian ini sudah fit, dapat diterima dengan baik. Hal tersebut dapat dilihat dari nilai chi square, CMID/DF, GFI, AGFI, RMSEA, TLI dan CFI yang hasilnya baik, dengan berdasarkan pada cut off value yang dipersyaratkan dalam persamaan model struktural.

\section{E. Pengujian Hipotesis}

Berikut ini adalah output table pengujian hipotesis penelitian dengan menggunakan alat uji AMOS Versi 22.0 dalam bentuk output Regression Weights seperti pada tabel 8 berikut:

Tabel 8

Regression Weights: (Group number 1 - Default model)

\begin{tabular}{|c|c|c|c|c|c|c|}
\hline & & & Estimate & S.E. & C.R. & $\mathrm{P}$ \\
\hline Persepsi Manfaat & $<---$ & Persepsi Kemudahan Penggunaan & .234 & .074 & 3.147 & .002 \\
\hline Persepsi Kepercayaan & $<---$ & Kepercayaan Sosial & .120 & .097 & 1.238 & .216 \\
\hline Persepsi Kepercayaan & $<---$ & Persepsi Reputasi & .059 & .099 & .600 & .548 \\
\hline Persepsi Kepercayaan & $<---$ & Persepsi Manfaat & .355 & .099 & 3.595 & $* * *$ \\
\hline Persepsi Kepercayaan & $<---$ & Resiko & -.241 & .118 & -2.033 & .042 \\
\hline Persepsi Kepercayaan & $<---$ & Persepsi Kemudahan Penggunaan & .195 & .077 & 2.546 & .011 \\
\hline Kesediaan Membeli & $<---$ & Persepsi Kepercayaan & .781 & .156 & 5.012 & $* * *$ \\
\hline
\end{tabular}

Sumber: data primer diolah 2017 (Output AMOS 22.0) 
Hasil pengujian ini menunjukkan bahwa dari tujuh jalur yang dianalisis terdapat 2 jalur yang tidak signifikan, terlihat dari besarnya tingkat signifikansi (p) uji hipotesis yang lebih besar dari 5\%. Kedua jalur tersebut adalah pengaruh kepercayaan sosial pada persepsi kepercayaan dan pengaruh persepsi reputasi pada persepsi kepercayaan.

1. H1: Kepercayaan sosial (KS) berpengaruh positif terhadap persepsi kepercayaan (PK). Hasil pengujian pada Tabel 8, menunjukkan nilai C.R. kepercayaan sosial pada persepsi kepercayaan sebesar 1,238 signifikan pada tingkat signifikansi $\mathrm{p}>0,05$, maka dapat disimpulkan bahwa hipotesis 1 tidak didukung.

2. H2: Resiko (R) mempunyai hubungan negatif terhadap persepsi kepercayaan (PK).

Hasil pengujian pada Tabel 8, menunjukkan nilai C.R. resiko pada persepsi kepercayaan sebesar $-2,033$ signifikan pada tingkat signifikansi $\mathrm{p}<0,05$, maka dapat disimpulkan bahwa hipotesis 2 didukung.

3. H3: Persepsi manfaat (PM) berpengaruh positif terhadap persepsi kepercayaan (PK).

Hasil pengujian pada Tabel 8, menunjukkan nilai C.R. persepsi manfaat pada persepsi kepercayaan sebesar 3,595 signifikan pada tingkat signifikansi $\mathrm{p}<0,05$, maka dapat disimpulkan bahwa hipotesis 3 didukung.

4. H4: Persepsi kemudahan penggunaan (PKP) berpengaruh positif terhadap persepsi manfaat (PM).

Hasil pengujian pada Tabel 8, menunjukkan nilai C.R. persepsi kemudahan penggunaan pada persepsi manfaat sebesar 3,147 signifikan pada tingkat signifikansi $\mathrm{p}<0,05$, maka dapat disimpulkan bahwa hipotesis 4 didukung.

5. H5: Persepsi kemudahan penggunaan (PKP) berpengaruh positif terhadap persepsi kepercayaan (PK).

Hasil pengujian pada Tabel 8, menunjukkan nilai C.R. persepsi kemudahan penggunaan pada persepsi kepercayaan sebesar 2,546 signifikan pada tingkat signifikansi $\mathrm{p}<0,05$, maka dapat disimpulkan bahwa hipotesis 5 didukung.

6. H6: Persepsi reputasi (PR) berpengaruh positif terhadap persepsi kepercayaan (PK).

Hasil pengujian pada Tabel 8, menunjukkan nilai C.R. persepsi reputasi pada persepsi kepercayaan sebesar 0,600 signifikan pada tingkat signifikansi $p>0,05$, maka dapat disimpulkan bahwa hipotesis 6 tidak didukung.

7. H7: Persepsi kepercayaan (PK) berpengaruh positif terhadap kesediaan membeli secara online (KM).

Hasil pengujian pada Tabel 8, menunjukkan nilai C.R. persepsi kepercayaan pada kesediaan membeli secara online sebesar 5,012 signifikan pada tingkat signifikansi $\mathrm{p}<0,05$, maka dapat disimpulkan bahwa hipotesis 7 didukung.

\section{KESIMPULAN}

A. Persepsi kepercayaan sosial tidak berpengaruh terhadap kepercayaan dalam melakukan pembelian online oleh para guru SD di Kabupaten Bantul. Hal ini berarti tinggi rendahnya kepercayaan orang lain terhadap online shopping tidak berpengaruh pada kepercayaan diri seseorang untuk melakukan pembelian online.

B. Para guru SD di Kabupaten Bantul menganggap bahwa semakin tinggi resiko akan suatu pelayanan pembelian online, maka kepercayaan para guru SD di kabupaten Bantul terhadap online shopping akan semakin menurun. Hal tersebut dikarenakan para guru SD tersebut tidak mau mengambil resiko dengan kehilangan uang atau yang lainnya, untuk sesuatu yang beresiko dengan bertransaksi melalui website online di internet.

C. Semakin tinggi persepsi manfaat yang dirasakan oleh para guru SD di Kabupaten Bantul terhadap online shopping, maka mereka semakin mempercayai online shopping. 
D. Semakin tinggi persepsi kemudahan penggunaan online shopping di kalangan guru SD di Kabupaten Bantul, maka semakin tinggi pula tingkat manfaat yang dirasakan dalam melakukan transaksi belanja secara online.

E. Peningkatan tingkat persepsi kemudahan penggunaan online shopping akan meningkat pula tingkat kepercayaan terhadap online shopping di kalangan guru SD di Kabupaten Bantul.

F. Persepsi reputasi online shopping tidak berpengaruh positif terhadap kepercayaan pada online shopping. Para guru SD di Kabupaten Bantul tidak atau kurang memperhatikan reputasi dari online shopping. Hal tersebut dikarenakan mereka biasanya menggunakan online shopping, apabila untuk memenuhi kebutuhan yang mendesak dan barang atau jasa yang dicari tidak ada di pasar maupun di toko biasa.

G. Persepsi kepercayaan terhadap online shopping di kalangan guru SD di Kabupaten Bantul, berpengaruh positif terhadap kesediaan untuk membeli secara online. Semakin tinggi tingkat kepercayaan terhadap belanja online, semakin tinggi pula kesediaan untuk melakukan belanja online.

\section{SARAN}

\section{A. Keterbatasan}

Keterbatasan pada penelitian ini antara lain:

1. Kemungkinan para responden berbeda-beda dalam mengartikan kalimat-kalimat yang ada dalam kuesioner.

2. Variabel-variabel yang digunakan dalam penelitian ini hanya terdiri dari: kepercayaan sosial, resiko, persepsi reputasi, persepsi manfaat, persepsi kemudahan penggunan, persepsi

B. Saran kepercayaan.

Saran untuk penelitian selanjutnya adalah:

a. Pada saat pengisian kuesionar, perlu dijelaskan maksud dari pertanyaan-pertanyaan yang ada di kuesioner kepada responden.

b. Pada saat pengisian kuesionar, peneliti mendampingi dan mewancarai responden lebih mendalam.

c. Menambah variabel-variabel baru yang berhubungan dengan online shopping, seperti: barang atau jasa yang dibutuhkan, harga, kecepatan pelayanan, kualitas tampilan website.

\section{DAFTAR PUSTAKA}

Ainur, R., 2007, Pengaruh Dimensi Kepercayaan (trust) Terhadap Partisipasi Pelanggan Ecommerce (Studi Pada Pelanggan E-Commerce di Indonesia). Tesis FPS Universitas Brawijaya-Malang.

Alba, J., Lynch, J., Weitz, B., Janiszewski, C., Lutz, R., Sawyer, A., \& Wood, S., 1997, Interactive home shopping: Consumer, retailer, \& manufacturer incentives to participate in electronic marketplaces. Journal of Marketing, 61, 38-53.

Al-Maghrabi, T.\& Dennis, C., 2010, Driving online shopping: Spending \& behavioral differences among women in Saudi Arabia. International Journal of Business Science \& Applied Management.

Brownn, M.W. \& Cudeck, R., 1993, Testing structural equation modelling Bollen, Kenneth A.; Long, J. Scott. NewburyPark: Sage Publications.

Chen, Y. H., \& Stuart, B., 2007, Initial trust \& online buyer behaviour. Industrial Management \& Data Systems, 107, 21-36. 
Corbit, B. J., Thanasankit, T., dan Yi, H., 2003, Trust and E-commerce: a study of consumer perceptions, Electronic commerce Research and Application, 2:203-215.

Davis, F. D., 1989, Perceived usefulness, perceived ease of use, \& user acceptance of information technology.MIS Quarterly, 13, 319-340.

Delhey, Jan and Kenneth, N., 2005, "Predicting Cross-National Levels of Social Trust: Global Pattern or Nordic Exceptionalism?” European Sociological Review, 21 (4): 311-327.

Doney, P. M., dan Canon, J.P., 1997, An examination of the nature of trust in buyer seller relationships. Journal of Marketing April 35-51.

Donthu, N., dan Gracia, A., 1999, The Internet Shopper, Journal of Advertising Research 39 (3), $52-58$.

Eastlick, M. A., 1996, Consumer intention to adopt interactive teleshopping. Marketing Science Institute Working Paper, Cambridge, MA: Marketing Science Institute: 96-113.

Flavian, C. \& Guinaliu, M., 2006, Consumer trust, perceived security \& privacy policy three basic elements of loyalty to a web site. Industrial Management \& Data System,106, 601-620.

Fitrianti, N, W., 2009, Pengaruh Kepercayaan dan Persepsi Resiko Terhadap Penggunaan Internet Banking di Kota Medan, Skripsi S-1, Fakultas Ekonomi, Universitas Islam Indonesia, Yogyakarta.

Foley, P. \& Sutton, D., 1998, Boom time for electronic commerce-rhetoric or reality. Business Horizons, pp. 21-30.

Gefen, D., 2004, "What Makes an ERP Implementation Relationship Worthwhile: Linking Trust Mechanism and ERP Usefulness", Juornal Management Information System, Vol 21(1), 275-301.

George, J. F., 2004, The theory of planned behavior \& internet purchasing. Internet Research,14, 198-212.

Geykens, I., Steenkamp, J.B.E.M., Scheer, L.K., \& Kumar, N., 1996, The Effect of Trust and Interdependence on Relationship Commitment: A Trans-Atlantic Study. International Journal of Research in Marketing, 13(4), 303-317.

Ghozali, I., 2013, Aplikasi Analisis Multivariate dengan Program SPSS. Edisi ketujuh. Badan Penerbit Universitas Diponegoro: Semarang.

Hair, et al. 2006. Multivariate Data Analysis $6^{\text {th }}$ Ed. New Jersey: Pearson Education.

Hashim, N. H., and Murphy, J., 2007, Brandingon The Web: Evolving Domain Name Usage Among Malaysian Hotels, Tourism Management, 28 (2), 621-624.

Hermawati, 2010, Pengaruh Kepercayaan, Resiko dan Sikap Konsumen Terhadap Kesediaan Berbelanja Secara Online, Skripsi S-1, Fakultas Ekonomi, Universitas Islam Indonesia, Yogyakarta.

Hu, L. \& Bentler, P.M., 1999, Cutoff criteria for fit indexes in covariance structure analysis: Conventional criteria versus new alternatives. Structural Equation Modeling, 6, 1-55.

Indrajit, R. E., 2001, E-Commerce: Kiat dan Strategi Bisnis di Dunia Maya, PT Elex Media Komputindo, Jakarta.

Jarvenpaa, Sirkka L., Joam, T., and L. Saarinen., 1999, Consumer Trust in An Internet Store: A Cross-Cultural Validation, Journal of Computer Mediated Communication, 5 (2). http://www.ascusc.org/jcmc/vol5/issue2. 
Jogiyanto, H. M., 2004, Metode Penelitian Bisnis: Salah Kaprah dan Pengalaman-Pengalaman, BPFE-Yogyakarta.

Kaman, L., 2009, Gender differences in Hong Kong adolescent consumers' green purchasing behavior, Journal of Consumer Marketing, Vol. 26 Issue: 2, pp.87-96.

Klein, L. R., 1998, Evaluating the potential of interactive media through new lens: Search versus experience goods. Journal of Business Research, 41,195-203.

Kotler dan Keller, 2009, Manajemen Pemasaran. Jilid I. Edisi 13, Erlangga -Jakarta.

Kassim, N, M., dan Abdulla, A. K., Mohammed, A, 2006, The Influence of Attraction on Internet Banking: An Extension to The Trust-Relationship Commitment Model, International Journal of Bank Marketing, Vol. 24, No. 6, 2006, Page 424-442.

Koufaris, M., \& Sosa, W. H., 2004, The development of initial trust in an online company by new customer.Information \& Management 41, 377-397.

Liang, T. P. \& Huang, J. S., 1998, An empirical study on consumer acceptance of products in electronic markets: a transaction cost model. Decision Support System, 24, 29-43.

Liao, Z. and Cheung M., 2001, Internet-based e-shopping and consumer attitudes: An Empirical Study, Journal of Information \& Management, 38(5): 299-306.

Limayem, M. And Khalifa, M., 2000, What Makes Consumers Buy From Internet? A Longitudinal Study of Online Shopping, IEEE Transaction on System Man and Cybernetics-Part A, Vol. 30 No. 4, July 2000, pg. 421-432.

Malaga, R. A., 2001, Web-Based Reputation Management System: Problems and Suggested Solutions, Electronic Commerce Research, $1 \quad$ (4), pp. 403. http://proquest.umi.com/pqdweb?index=6\&did.

Mayer, R. C., Davis, J.H., dan Schoorman, F. D., 2007, An Integrative Model of Organizational Trust: Past, Present and Future, Academy of Management Review, Vol. 32, No.2, pg. 344354.

McKnight, D. H., Choudhury, V., dan Kacmar, C., 2002, Developing and Validating Trust Measures for E-Commerce: An Integrative Typology. Information Systems Research 334359.

McLeod, R. and Schell, G. P., 2004, Management Information systems. Ninth Edition. Pearson Education Inc., New Jersey.

Mukherjee, A., Nath, P., 2003, A Model of Trust in Online Relationship Banking, The International Journal of Banking Marketing Bradforf, 21 (1).

Mutz, D, C., 2005, Social Trust and E-commerce: Experimental Evidence For The Effect of Social Trust on Individuals Economic Behavior, Public Opinion Quarterly; Fall 2005; 69,3; ABI/INFORM Global pg.393.

Palupi, M \& Tjahjono, H.K., 2008. Aplikasi Technology Acceptance Model dengan Mempertimbangkan Gender Pada Perilaku Penggunaan Internet. Jurnal Ekonomi dan Bisnis, 9 (2):147-166

Pavlou, P, A., 2003, Consumer Acceptance of Electronic Commerce: Integrating Trust and Risk With The Technology Acceptance Model, International Journal of Electronic Commerce, 101-134. 
Rotter, J. B., 1967, A New Scale For The Measurement of Interpersonal Trust, Journal of Personality, 35, pg. 651-665.

Santoso, S., 2014, Statistik Multivariat Edisi Revisi. PT Elex Media Komputindo: Jakarta.

Sekaran, U., 2006, Research Methods for Business, a Skill -Building Approach. John Wiley \& Sons, Inc. Canada.

Sekaran, U., dan Roger, B., 2010, Edisi 5, Research Method For Business: A Skill Building Approach. John Wiley @ Sons, New York.

Seligman, A., 1997, Social Interaction: Trust: Social Rule, Book (ISBN 0691012423), P. 231.

Seo \& Kim., 1999, An empirical study in effects of cost advantage in online transaction: Customer perception of use of internet shopping malls.Proceedings of Korean Academic Society of Business Administration, Spring Conference pp. 225-234.

Seyal, A. H., \& Rahman, A. M. N., 2003, Student use of the internet: An extension of TAM in technical \& vocational institutions in Brunei Darussalam. AJIS10.

Shankar, V., Urban, G. L. \& Sultan, F., 2002, Online trust: A stakeholder perspective, concepts, implications, \& future directions. Journal of Strategic Information Systems, 113, 325-344.

Shim, M. A. E., Sherry L. L., \& Warnington, P., 2001, An online purchase intentions model: The role of intention to search. .Journal of Retailing,77, 397-416.

Shu, Jing Ou, 2003, Identifying The Factors That Affect Consumers Willingness to do Internet Shopping, Masters Thesis, Concordia University.

Slameto, 2010, Belaja dan Faktor-Faktor yang Mempengaruhinya. Rineka Cipta: Jakarta.

Steiger, J. H., 1990, Structural model evaluation and modification: An interval estimation Approach. Multivariate Behavioral Research, 25, 173-180.

Stevanus, W, W., 2005, Kajia Teoritis Technology Acceptance Model Sebagai Model Pendekatan Untuk Menentukan Strategi Mendorong Kemauan pengguna Dalam Menggunakan Teknologi Informasi dan Komunikasi.

Suh, B., \& Han, I., 2003, The impact of customer trust \& perception of security control on the acceptance of electronic commerce. International Journal of Electronic Commerce, 7, 135161.

Sumiyana, 2006, Model Komitmen Multidimensional Atas Pilihan Adopsi Sistem dan Perilaku Pemraktikan (Study Empiris di Jogjakarta), Simposium Akuntansi 9, Padang.

Supardi, 2005, Metode Penelitian Untuk Ekonomi dan Bisnis, Ekonisia Universitas Islam Indonesia, Yogyakarta.

Tjahjono, H.K., 2015, Metode Penelitian Bisnis. VSM MM UMY

Tjahjono, H.K. \& Wulandari, Y., 2008, Implementasi model penerimaan teknologi pada organisasi: kajian intensi dosen menggunakan teknologi e-learning, Modus Jurnal Ekonomi dan Bisnis, 20(1):42-51

Tjahjono, H.K. \& Palupi, M., 2014, Model konseptual intensi berwirausaha berbasis teknologi informasi. Jurnal Bisnis Teori dan Implementasi, 5(1):1-8

Triandis, H., 1980, Values, attitudes, and interpersonal behavior. In M. M. Page (Ed.), Nebraska Symposium on Motivation, 1979: Beliefs,Attitudes, and Values (pp. 195-259). University of Nebraska Press, Lincoln, NB.

Wijanto, S, H., 2008, Structural Equation Modeling dengan Lisrel 8.8, Graha Ilmu: Yogyakarta. 
Weber, K. \& Roehl, W.S., 1999, Profiling people searching for \& purchasing travel product on the world wide web. Journal of Travel Research, 37, 291-298.

Yaobin, Lu \& Tao, Z., 2007, A research of consumers' initial trust in online store in China. Journal of Research \& Practice in Information Technology, 39. 